- This paper provides useful feedback from patients regarding dentists' current rates of smoking cessation advice.

- Dental patients expect dentists to be interested in all relevant health issues. It appears that smoking cessation advice by dentists will not alienate patients who smoke.

- However, patients lack confidence in dentists' ability specifically to assist them to quit.

- Less than one in three smokers would make a quit attempt if advised by their dentist to do so.

- Smoking cessation advice by dentists is not self-evidently effective. To ensure that dentists maximise their limited time with patients, more rigorous research is required to establish efficacy of smoking cessation advice when delivered by dentists before admonishing changes in clinical practice.

\title{
Preventive dentistry: what do Australian patients endorse and recall of smoking cessation advice by their dentists?
}

\author{
G. Rikard-Bell, ${ }^{1}$ N. Donnelly ${ }^{2}$ and J. Ward ${ }^{3}$
}

\begin{abstract}
Objective To investigate patients' views regarding dentists' smoking cessation advice.

Design Survey questionnaire.

Setting One hundred and thirty five dental practices in Sydney Australia. Subjects Two thousand, four hundred and fifty one dental patients. Results One thousand, one hundred and sixty pre-consultation questionnaires were obtained (RR=80\%), $302(26 \%)$ were self-reported smokers. From these, 623 post-consultation questionnaires were returned $(\mathrm{RR}=54 \%)$. Most patients expected dentists to be interested in their smoking status ( $n=847 / 1160,73 \%, 95 \% \mathrm{Cl}: 70 \%$ to $76 \%$ ) and to discuss smoking with them ( $n=713 / 1160,61 \%, 95 \% \mathrm{Cl}: 59 \%$ to $64 \%)$, however, smokers were significantly less likely to respond as such compared with non-smokers $(P<0.001)$. Smokers and non-smokers equally would not change dentist even if asked about their smoking status opportunistically

( $59 \%$ versus $62 \%)(\mathrm{OR}=0.91,95 \% \mathrm{Cl}: 0.67$ to 1.22$)$. Less than one third of all smokers would try to quit if their dentist suggested they do so ( $n=90 / 302,30 \%, 95 \% \mathrm{Cl}: 25 \%$ to $35 \%)$. Smokers' recall of quit advice from their recent consultation was low $(n=22 / 124,18 \%)$.

Conclusions Smoking cessation advice by dentists is not self-evidently effective. These findings behove interventional research to ascertain efficacy of smoking cessation advice delivered by dentists before admonishing changes in routine clinical practice.
\end{abstract}

Results from studies examining whether dentists are effective in assisting their patients who smoke to quit are inconclusive. In one randomised controlled trial, advice by dentists in Indianapolis $(n=54)$ achieved sustained patient quit rates of $7.7 \%$ enhanced by their use of nicotine gum. ${ }^{1}$ However, three other well-designed studies failed to demonstrate significant results. $^{2-4}$ Specifically, a randomised controlled trial in Finland of a comprehensive intervention comprising annual inquiries of adolescents about their smoking, photographs of the harmful

\footnotetext{
${ }^{1}$ Senior Research Officer, ${ }^{2}$ Statistician, CSAHS Needs Assessment \& Health Outcomes Unit, ${ }^{3}$ (Formerly)Director, CSAHS Needs Assessment \& Health Outcomes Unit; (Currently) Director, Division of Population Health, South West Sydney Area Health Service Correspondence to: A/Prof Jeanette Ward, Director, Division of Population Health, South West Sydney Area Health Service, Locked Bag 7008, Liverpool 1871, Australia E-mail: Jeanette.Ward@swsahs.nsw.gov.au
}

\section{Refereed paper}

Received 18.07.01; Accepted 22.02.02

(c) British Dental Journal 2003; 194: 159-164 effects of smoking on dentition and brief advice by the dentist failed to demonstrate long-term ( $>2$ years) changes in adolescent smoking rates. ${ }^{2}$ Another randomised controlled trial in 75 Oregon dental practices demonstrated that a brief quit message from dental-hygienists was ineffective. ${ }^{3}$ A prospective study (non-randomised) conducted in 54 primary care dental practices in the United Kingdom was hindered by sustained reluctance of dental practice staff to recruit smokers into a smoking cessation advice programme, despite training and educational materials. ${ }^{4}$ Of 159 smokers enrolled in the programme, only $4 \%(n=7)$ attributed quitting to the dental intervention. ${ }^{4}$

As these results appear to be the sum of all rigorously acquired evidence to date, it is understandable that dentists are reluctant to initiate smoking cessation advice. ${ }^{5-11}$ Recently, recognised experts have called for better trials to provide health professionals, such as dentists, with a more compelling evidence-base. ${ }^{12}$

Dentists perceive that their patients do not consider smoking advice part of their dentist's professional role. ${ }^{5,8}$ They are fearful that providing smoking cessation advice may alienate patients or interfere with the dentist-patient relationship ${ }^{6,13-15}$ and that their patients lack the motivation to quit. ${ }^{10,15-16}$

We found only three studies attempting to determine the views of patients themselves. In the first of these, ${ }^{16}$ the authors report discrepancies between dentists' self-reported behaviour and findings of a concurrent community survey. Although $41 \%$ of dentists stated that they had advised smoking patients to quit, only $7 \%$ of smokers in the community reported that they had received this advice during dental visits. A subsequent study using householdface-to-face interviews of smokers in the United States found that less than one quarter had been advised to quit by their dentists in the previous year. ${ }^{17}$ The third and most recent study, conducted in Canada, involved telephone interviews with dental patients asking about any smoking cessation advice they received from their dentists during their last visit. ${ }^{8}$ Many patients (58.5\%) responded that dentists should routinely offer smoking cessation advice yet the majority of dentists (61.5\%) perceived that patients did not expect such smoking cessation advice. ${ }^{8}$

We have examined views of dentists in Sydney, Australia., ${ }^{5,6}$ Patients' motivation, perceptions of dentists as smoking counsellors and issues of patient alienation outranked lack of time, skills or financial reimbursement as perceived barriers to provision of routine smoking advice. ${ }^{5}$ We next designed the present study to 
determine smokers' receptivity to smoking cessation advice from their dentist, their motivation to quit, patient recall of smoking advice strategies used by their dentist and their perception of efficacy of such advice. We conducted our study in Central Sydney, a region with high smoking rates in New South Wales, the most populous Australian state. ${ }^{18}$

\section{METHODS}

\section{Subjects}

All dentists practising in the region served by the Central Sydney Area Health Service were asked to participate. A list purchased from a commercial mailing house was cross-checked against the most current telephone listings to ensure a complete sampling frame. Recruitment commenced in 1999 and continued until April 2000.

\section{Dentist recruitment}

All dentists were telephoned to advise them of the imminent arrival of a letter outlining our study. One week later, dentists were phoned again to arrange a convenient time to explain the study further and request consent to participate. Practices were considered ineligible if there was no receptionist, if the dentist was working less than one day per week within Central Sydney or if the proportion of ineligible patients (non-English speaking or paediatric) was $80 \%$ or more of the dentist's caseload. Both consenting and non-consenting dentists were asked to complete a brief questionnaire to ascertain socio-demographics. No training in the provision of smoking cessation advice was provided to dentists prior to recruitment.

\section{Patient recruitment}

Receptionists were trained to approach a consecutive sample of patients to complete a pre-consultation questionnaire. They were provided with tally sheets to record ineligible patients and refusals. Patients were considered ineligible if they were physically or mentally unable to participate, too old or too young, spoke insufficient English to complete the questionnaire unassisted or if they had previously completed a questionnaire. Participating patients also were asked to indicate their consent for a 'post-consultation' questionnaire to be posted to them within a few days of their consultation and, if agreed, to provide contact details. Completed pre-consultation questionnaires were sealed inside envelopes before being given to the receptionist who mailed them back to the researchers in secure bags. Regular telephone contact was maintained with receptionists to monitor compliance.

\section{Pre-consultation questionnaire}

Our pre-consultation questionnaire commenced with five questions to obtain demographic information. We next asked patients about their use of dental services. We also assessed patients' knowledge of the risks associated with smoking for two medical conditions (heart disease and lung cancer) and three oral health conditions (cancer of the mouth, delayed healing of mouth wounds, dental caries). Smoking is associated only with four of these, namely heart disease, lung cancer, oral cancer and delayed healing of mouth wounds. ${ }^{7}$

Patients then were asked to report the number of members of their household who they rated to be regular smokers and their own current smoking status. A series of questions determined 'stage of change.' 19

Using a 5-point Likert scale ('agree a lot' to 'disagree a lot'), all patients were next asked to respond to five statements about dentists providing smoking cessation advice. We then asked about nine specific strategies that they may have used during any quit attempts in the previous six months.

Smokers also were asked to rate their agreement ('agree a lot' to 'disagree a lot') with eight statements which elsewhere had been asked of dentists. ${ }^{5}$ Three of these addressed 'expectations' about dentists' role as providers of smoking cessation advice, five addressed specific smoking cessation 'strategies' that smokers may receive from their dentist.

\section{Post-consultation questionnaire}

In order to minimise recall bias, ${ }^{20}$ patients were mailed post-consultation questionnaires within one week of their attendance at the dental clinic. Non-responders received a telephone prompt one week from mail-out. ${ }^{21}$

In our post-consultation questionnaire, smokers only were asked to recall whether the dentist had provided any of ten strategies during their most recent consultation. We asked patients to recall whether their dentist had asked about their smoking status. They then were asked to rate their agreement to seven statements about dentists' provision of smoking advice ('agree a lot', 'agree', 'neither', 'disagree', 'disagree a lot').

\section{Data analyses}

Descriptive statistics were generated for dentist and patient participation and socio-demographics. Descriptive statistics and univariate analyses were calculated using an Epi Info statistical package. ${ }^{22}$ McNemar's tests were used for paired responses. When reporting 95\% confidence intervals, the CSAMPLE module of EpiInfo $6.04 \mathrm{c}$ was used to control for clustering of patient data within dental practitioner. ${ }^{23}$ Consent bias was examined.

Frequencies and corresponding percentages were calculated for patient responses to pre-consultation questionnaire items. Univariate analyses were undertaken to determine the relationship between patients' preferences of oral health advice from their dentist. Logistic regression models were undertaken for two outcome variables:

- Self-reported smoking status of patient ('never' versus other responses)

- Knowledge that smoking is a cause for the development of heart disease, lung cancer, oral cancer, delayed healing of mouth wounds ('yes' versus other responses) but not dental caries ('no' versus other responses).

Study variables for these models included: gender, age, selfreported smoking status, marital status ('married' versus other), language spoken at home ('English' versus other), higher education ('university or college degree' versus other) and whether other smokers were reported in the household ('yes' versus 'no').

Response bias was examined for patients' willingness to have a questionnaire posted to their home and for completing the post-consultation questionnaire. Frequencies and corresponding percentages next were calculated. Univariate analyses were undertaken for patients' smoking status and recall of being asked a specific question about their smoking status during their recent consultation. Comparisons were made with smoking detection and quit advice rates reported by dentists practising in the study region. ${ }^{5}$

SPSS for windows was used for logistic regressions. ${ }^{24}$ A manual backwards elimination procedure used whereby the least significant explanatory variable was removed in succeeding models until only significant variables (5\% significance level) remained. When examining bivariate relationships, the CSAMPLE module of Epi-Info 6.04c was used to control for the clustering of patients within dental practitioner. These relationships are expressed as odds ratios with 95\% CI which have take account of intra-cluster dependencies. A generalised estimating equations (GEE) approach was adopted when estimating odds ratios and associated confidence intervals for the regressions using a STATA statistical package (V5.0). ${ }^{25}$ 


\section{RESULTS}

\section{Dentist and patient recruitment}

Of 135 eligible dentists practising in Central Sydney, 78 (58\%) consented to participate. There was no significant difference in gender, self-reported smoking, age, year since graduation, practice type and work load between consenting and non-consenting dentists.

A total of 2,451 patients were approached to participate during the study period. Of these, 1,009 were ineligible for the study (293 non-English speaking; 163 too young or too old; 37 forgot reading glasses; 68 physically or mentally unwell; 209 dental practice restraints; 158 had participated previously; 81 other reason). Of those 1,442 eligible patients, 1,160 agreed to participate (80\% response rate). Younger patients were significantly more likely to agree to participate than older patients (85\% versus $81 \%$ ) $\left(\chi^{2}=4.18, \mathrm{df}=1, P=0.04\right)$. The number of patients recruited per dentist ranged from 1-73 $($ median $=16$, mode $=27)$.

\section{Pre-consultation patient questionnaire}

Table 1 summarises socio-demographic characteristics of the 1,160 participants. The age range of the sample was 18 to 94 (median $=42$ years; mode $=37$ years). Due to an administrative oversight, we ascertained gender only for 900 respondents (76\%). Of these, 377 were males (42\%) and 523 were females (58\%). The majority of patients reported having a regular dentist $(n=948 ; 82 \%)$ and being a patient of their regular dentist for more than 12 months $(n=857 ; 74 \%)$.

Of the sample, 302 (26\%) (95\% CI:23.6\% to 28.6\%) were selfreported current smokers. Those never married, living with a smoker and speaking English within the home each independently increased the likelihood of a patient having ever smoked (Table 2).

\section{Patients' knowledge of smoking related health conditions $(n=1,160)$}

A majority of respondents correctly indicated that smoking was a risk factor for the development of lung cancer $(n=1,056,91 \%)$, heart disease $(n=1,095,94 \%)$ and cancer of the mouth $(n=860$, $74 \%$ ). Significantly fewer patients knew the risks of smoking associated with cancer of the mouth than lung cancer (McNemars $\left.\chi^{2}=126.55, \quad \mathrm{df}=1, \quad P<0.001\right)$ or heart disease (McNemars $\left.\chi^{2}=196.55, \mathrm{df}=1, P<0.001\right)$. Just under half correctly indicated that smoking delays healing of mouth wounds $(n=570,49 \%)$ but few correctly identified that smoking does not increase the risk of oral caries $(n=145,13 \%)$.

\section{Patients' views regarding dentists' provision of smoking advice $(n=1,160)$}

Patients' views about dentists' provision of smoking cessation advice are summarised in Table 3. Smokers $(n=186 / 302)$ were significantly less likely than non-smokers $(n=661 / 858)$ to hold positive views about dentists' interest in their smoking status (62\% versus $77 \%)(\mathrm{OR}=0.48,95 \% \mathrm{CI}$ : 0.36 to 0.63$)$ and discussing smoking (smokers: $n=145 / 302$, non-smokers: $n=568 / 858)(48 \%$ versus $66 \%)(\mathrm{OR}=0.47,95 \% \mathrm{CI}$ : 0.37 to 0.60$)$. However, most patients would not change dentist if asked about their smoking status opportunistically during every visit $(n=708,61 \%)$. Further, similar proportions of current smokers $(n=179 / 302)$ and current non-smokers ( $n=529 / 858)$ (59\% versus 62\%) (OR $=0.91,95 \% \mathrm{CI}$ : 0.67 to 1.22 ) held this view.

\section{'Stage of change' and previous quit attempts}

Nearly half of the smoking patients ( $n=139 / 302,46 \%)$ were not seriously considering quitting ('pre-contemplation'). Only 79 smokers ( $n=79 / 302,26 \%$ ) were considering quitting ('contemplation') and 41 ( $n=41 / 302,14 \%)$ had made an attempt to do so ('preparation'). The distribution of 'stage of change' for dental patients was not significantly different from that determined for a community sample of residents of Central Sydney $\left(\chi^{2}=0.80, \mathrm{df}=2, P=0.67\right){ }^{26}$ A majority of ex-smokers $(n=$ 205/287, 71\%) had sustained their abstinence over the past 6 months ('action').

When smokers were asked which strategies they had used in the past six months to assist them to quit smoking, significantly more responded that they had attempted to quit 'cold turkey' ( $n=87 / 302,29 \%$ ) than used nicotine replacement therapy $(n=42 / 302,14 \%)$ (McNemars $\left.\chi^{2}=20.38, \mathrm{df}=1, P<0.001\right)$. However, nearly one fifth of smokers attempting to quit had tried by gradually cutting down ( $n=58 / 302,19 \%)$, an ineffective

\begin{tabular}{|c|c|c|c|c|}
\hline & & $N$ & $\% 0^{*}$ & 1996 Census $\% 28$ \\
\hline \multicolumn{5}{|l|}{ The characteristics of participating patients } \\
\hline \multirow[t]{2}{*}{ Age } & $18-39$ & 500 & 43 & 37 \\
\hline & $\geq 40$ & 619 & 53 & 41 \\
\hline \multirow[t]{2}{*}{ Language spoken (home) } & English & 401 & 35 & 66 \\
\hline & Other & 752 & 65 & 44 \\
\hline \multirow[t]{3}{*}{ Marital status } & Never married & 284 & 24 & 38 \\
\hline & Married/ defacto & 666 & 57 & 45 \\
\hline & Other & 172 & 15 & 13 \\
\hline \multirow[t]{4}{*}{ Education } & Did not complete primary & 6 & $<1$ & \\
\hline & Completed primary & 617 & 53 & \\
\hline & University/college degree & 468 & 40 & \\
\hline & Other & 62 & 5 & \\
\hline \multirow[t]{2}{*}{ Employment status } & Employed & 817 & 70 & \\
\hline & Not in labour force & 326 & 28 & \\
\hline \multicolumn{5}{|l|}{ Patient dental utilisation } \\
\hline \multirow[t]{2}{*}{ Do you have a regular dentist? } & Yes & 948 & 82 & \\
\hline & No & 203 & 18 & \\
\hline How long have you been a patient & $<12$ months & 127 & 11 & \\
\hline \multirow[t]{2}{*}{ of your regular dentist? } & $\geq 12$ months & 857 & 74 & \\
\hline & No regular dentist & 135 & 12 & \\
\hline Is this the first time ever that you & Yes & 138 & 12 & \\
\hline have seen this dentist? & No & 1,013 & 87 & \\
\hline How long have you been a patient & $<12$ months & 344 & 30 & \\
\hline of the dentist you are seeing today? & $\geq 12$ months & 801 & 69 & \\
\hline
\end{tabular}




\begin{tabular}{|c|c|c|}
\hline Variable & $\begin{array}{l}\text { Univariate } \\
\text { odds ratio } \\
\text { (adjusted for clustering) }\end{array}$ & $\begin{array}{l}\text { GEE odds ratio } \\
\text { adjusted association }\end{array}$ \\
\hline \multicolumn{3}{|l|}{ Language } \\
\hline English & 1.00 & 1.00 \\
\hline Other & $1.19(0.94-1.46)$ & $1.41(1.10-1.82)$ \\
\hline \multicolumn{3}{|l|}{ Marital } \\
\hline Ever married & 1.00 & 1.00 \\
\hline Never married & $1.20(0.87-1.63)$ & $1.39(1.02-1.91)$ \\
\hline \multicolumn{3}{|l|}{ Living with a smoker } \\
\hline No & 1.00 & 1.00 \\
\hline Yes & $4.67(3.57-6.11)$ & $5.07(3.80-6.76)$ \\
\hline
\end{tabular}

strategy. ${ }^{27}$ Less than 5\% of smokers had used self-help smoking group/clinic, written manual/book, drugs, hypnosis, acupuncture or a support group.

\section{Smokers' views about smoking cessation advice in dentistry $(n=302)$}

Smokers' had low 'expectations' about smoking cessation advice in dentistry (Table 3). Further, with respect to 'strategies', while a majority would appreciate their dentist advising them about the effects of smoking on oral health, significantly fewer were positive about dentists' provision of practical advice about how to stop smoking (64\% versus 41\%) (McNemars $\chi^{2}=28.3$, $\mathrm{df}=1$, $P<0.001$ ) or being given written information (64\% versus $39 \%$ ) (McNemars $\chi^{2}=24.6, \mathrm{df}=1, P<0.001$ ). Less than one third of all smokers surveyed would try to quit if their dentist suggested they do so ( $n=90 / 302,30 \%, 95 \%$ CI: $25 \%$ to $35 \%$ ). While $40 \%$ of smokers $(n=120 / 302)$ were considering quitting or had made an attempt to do so ('contemplation' or 'preparation'), only about a third of these would try to quit if their dentist advised them to do so $(n=44 / 120,37 \%)$.

\section{Post-consultation patient questionnaire}

Response rate

Of 1,160 patients who completed pre-consultation questionnaires, $849(73 \%)$ agreed to have a post-consultation questionnaire forwarded to their home. Univariate analyses demonstrated that non-smokers were significantly more likely than smokers to agree to being posted a post-consultation questionnaire $(75 \%$ versus $68 \%)$ ( $\mathrm{OR}=1.42,95 \% \mathrm{CI}: 1.08$ to 1.87$)$, as were older patients $(=40)$ compared with younger patients $(O R=$ 1.56, 95\% CI: 1.06 to 2.30). Further, non-English speaking patients were also significantly more likely than English speaking patients to agree to being posted a post-consultation questionnaire (OR $=2.44,95 \% \mathrm{CI}: 1.77$ to 3.36$)$.

From those 849 who agreed, 623 (73\%) returned post-consultation questionnaires. Smokers were significantly less likely than non-smokers to return post-consultation questionnaires (60\% versus $77 \%)(\mathrm{OR}=0.44,95 \% \mathrm{CI}: 0.31$ to 0.63$)$ as were younger patients compared with older patients (64\% versus $80 \%)(\mathrm{OR}=0.45,95 \% \mathrm{CI}$ : 0.33 to 0.63 ). Male patients were also significantly less likely to return post-consultation questionnaires than female patients (67\% versus 78\%) (OR $=0.57,95 \% \mathrm{CI}: 0.41$ to 0.78$)$.

\section{Respondents' views about smoking advice provided by dentist $(n=623)$}

Table 4 summarises patients' responses to seven statements regarding their most recent consultation. Significantly more smokers agreed with the statement that 'dentists should not be giving smoking cessation advice' than non-smokers (33\% versus $20 \%)(\mathrm{OR}=1.97,95 \% \mathrm{CI}: 1.25$ to 3.11$)$.
Table 3 Patients' and smokers' responses to statements about smoking cessation advice by dentists: pre-consultation questionnaire

\begin{tabular}{lrr}
\hline Patients' responses to five statements $(n=1,160)$ & $N$ & $\% *$ \\
\hline I would expect my dentist to be interested in the smoking status & & \\
of his/her patients & 847 & 73 \\
Agree + strongly agree & 148 & 13 \\
Neither & 92 & 8 \\
Disagree + strongly disagree & & \\
& & \\
I would expect my dentist to discuss smoking with their patients & 713 & 61 \\
Agree + strongly agree & 225 & 19 \\
Neither & 149 & 13 \\
Disagree + strongly disagree &
\end{tabular}

I would change to another dentist if the dentist asked me about mysmoking this visit

Agree + strongly agree

Neither

Disagree + strongly disagree

I would change to another dentist if the dentist asked about my smoking every visit

Agree + strongly agree

Neither

Disagree + strongly disagree

I think that smoking advice provided by dentists to their patients should be covered by insurance

Agree + strongly agree

Disagree + strongly disagree

Smokers' responses to eight statements $(n=302)$

Smokers' expectations

I would expect my dentist to discuss my smoking every visit

Agree + strongly agree

Neither

Disagree + strongly disagree

I would expect my dentist to discuss my smoking this visit

Agree + strongly agree

Neither

Disagree + strongly disagree

I would appreciate my dentist helping me to stop smoking

Agree + strongly agree

Neithe

Disagree + strongly disagree

Smokers' views about specific strategies

I would appreciate my dentist advising me about the effects of smoking on my oral health

Agree + strongly agree

Neither

Disagree + strongly disagree

I would appreciate my dentist giving me practical advice about how to stop smoking

Agree + strongly agree

Neither

Disagree + strongly disagree

I would appreciate my dentist giving me written information about quitting

Agree + strongly agree

Neither

Disagree + strongly disagree

If my dentist referred me to a GP, I would go

Agree + strongly agree

Neither

Disagree + strongly disagree

If my dentist suggested that I quit smoking, I would try

Agree + strongly agree

Neither

Disagree + strongly disagree 


\begin{tabular}{|c|c|c|}
\hline Patients' responses & $N$ & $\% *$ \\
\hline \multicolumn{3}{|c|}{$\begin{array}{l}\text { Dentists should be interested in all health issues relevant } \\
\text { to their patient }\end{array}$} \\
\hline Agree + strongly agree & 395 & 63 \\
\hline Neither & 92 & 15 \\
\hline Disagree + strongly disagree & 123 & 20 \\
\hline \multicolumn{3}{|c|}{$\begin{array}{l}\text { Patients want their dentist to take an interest in all } \\
\text { health issues relevant to them }\end{array}$} \\
\hline Agree + strongly agree & 345 & 55 \\
\hline Neither & 118 & 19 \\
\hline Disagree + strongly disagree & 140 & 22 \\
\hline \multicolumn{3}{|c|}{ Dentists should provide good oral care, nothing more } \\
\hline Agree + strongly agree & 190 & 30 \\
\hline Neither & 49 & 8 \\
\hline Disagree + strongly disagree & 368 & 59 \\
\hline \multicolumn{3}{|c|}{ Dentists should not be giving smoking cessation advice } \\
\hline Agree + strongly agree & 141 & 23 \\
\hline Neither & 113 & 18 \\
\hline Disagree + strongly disagree & 348 & 56 \\
\hline \multicolumn{3}{|c|}{$\begin{array}{l}\text { Dentists should take care of oral health issues only and } \\
\text { doctors should take care of other general health issues }\end{array}$} \\
\hline Agree + strongly agree & 232 & 37 \\
\hline Neither & 97 & 16 \\
\hline Disagree + strongly disagree & 282 & 45 \\
\hline \multicolumn{3}{|c|}{ Dentists do not know how to stop patients smoking } \\
\hline Agree + strongly agree & 158 & 25 \\
\hline Neither & 213 & 34 \\
\hline Disagree + strongly disagree & 221 & 35 \\
\hline \multicolumn{3}{|l|}{ Many dentists themselves smoke } \\
\hline Agree + strongly agree & 128 & 21 \\
\hline Neither & 343 & 55 \\
\hline Disagree + strongly disagree & 110 & 18 \\
\hline
\end{tabular}

\section{Patients' recall of dentists' smoking status detection}

of 623 patients who returned post-consultation questionnaires, only $117(19 \%)$ recalled that their dentist had asked about their smoking status during their most recent consultation. Recall of this question was significantly higher among smokers ( $n=40 / 124)$ compared with non-smokers $(n=77 / 499)$ (32\% versus $15 \%)(\mathrm{OR}=1.55,95 \% \mathrm{CI}: 0.96$ to 2.51$)$. The proportion of patients who recalled a specific question about their smoking status did not differ from the proportion of Central Sydney dentists who previously reported 'always' asking this question of patients $(19 \%$ v $14 \%)\left(\chi^{2}=1.80, \mathrm{df}=1, P=0.18\right) .^{5}$

\section{Smokers' recall of smoking advice provided by dentist during most recent consultation $(n=124)$}

When asked to recall which smoking cessation advice strategies were provided during their most recent dental consultation, less than one third of smokers recalled each of ten strategies (Table 5). Smokers were significantly more likely to recall receiving advice about the oral health effects of smoking rather than the next most commonly recalled strategy, namely advice to quit (McNemars $\chi^{2}=$ 8.52, $\mathrm{df}=1, P<0.01)$.

Nevertheless, the percentage of smokers' recall of advice about the effects of smoking on their oral health was significantly higher than the proportion of Central Sydney dentists who reported 'always' providing this advice to patients (32\% v 14\%) $\left(\chi^{2}=10.03\right.$, $\mathrm{df}=1, P=0.001) .{ }^{5}$ However, smokers' recall of advice to quit was not significantly different from the proportion of Central Sydney dentists who reported always providing this advice (19\% v 13\%) $\left(\chi^{2}=1.32, \mathrm{df}=1, P=0.25\right) .^{5}$
Table 5 Smokers' recall of ten smoking cessation strategies delivered by dentists during their most recent consultation: Post-consultation questionnaire $(n=124)$

\begin{tabular}{lccr}
\hline Dentist behavioural advice & $\begin{array}{c}\text { N stating } \\
\text { 'Yes' }\end{array}$ & $\%$ & $95 \% \mathrm{Cl}$ \\
\hline $\begin{array}{l}\text { Tell you about the effects of smoking on } \\
\text { your oral health }\end{array}$ & 37 & 30 & $18-46$ \\
$\begin{array}{l}\text { Advise you to quit smoking } \\
\text { Tell you about the health risks }\end{array}$ & 22 & 18 & $11-27$ \\
$\quad$ due to smoking & 17 & 14 & $6-23$ \\
$\begin{array}{l}\text { Suggest nicotine replacement therapy } \\
\text { Give hints on how to stop smoking }\end{array}$ & 6 & 5 & $1-10$ \\
Suggest you set a 'quit' date & 5 & 4 & $1-8$ \\
Offer anything to read about giving & 5 & 4 & $1-8$ \\
$\quad$ up smoking & 4 & 3 & $1-7$ \\
Give advice on how to 'cut down' & 4 & 3 & $1-7$ \\
Refer to a GP to discuss smoking & 3 & 2 & $0.3-5$ \\
Refer to a clinic or anti-smoking group & 3 & 2 & $0.4-6$
\end{tabular}

Overall, only 35\% ( $n=44 / 124)$ of smokers recalled any type of smoking cessation advice from their dentist during their recent consultation. There were no independent predictors of recall of smoking advice. Recall of any smoking cessation advice strategy by smokers considering quitting ('contemplation') was low, only $16 \%(n=13 / 79)$ reported such advice. Further, only four $(n=4 / 41$, $10 \%$ ) smokers who had made a quit attempt ('preparation') recalled any smoking cessation advice strategy.

\section{DISCUSSION}

Our method involving pre- and post- consultative questionnaires of patients attending community-based dental practice has generated unique data about perceptions and recall of smoking cessation advice by their dentists. First, the majority of patients seen in dental practices have a long-term ( $>12$ months) relationship with a regular dentist indicating that dentists are ideally suited to provide smoking cessation advice. Further, a majority of respondents expected their dentist to be interested in all health issues ( $n=395 / 623,63 \%)$. Only a minority agreed that dentists should not provide smoking advice ( $n=141 / 623,23 \%)$. That significantly fewer patients knew that smoking was a cause for oral cancer compared with the proportion who knew the association between smoking and other diseases, demonstrates the potential for public health intervention.

Encouragingly, most dental patients (smokers and non-smokers) in our survey ( $\mathrm{n}=708 / 1160,61 \%)$ would not change to another dentist if asked about smoking opportunistically at every visit. It seems that dentists' fears that smoking advice may alienate patients may be unwarranted. ${ }^{5}$ Australian and Canadian dentists perceive that their patients' motivation to quit smoking mitigates their provision of smoking advice. ${ }^{5,15}$ Less than one third of all smokers surveyed would try to quit if their dentist suggested they do so $(n=$ 90/302, 30\%). This low acceptability of Australian smokers to a 'quit message' delivered by their dentist appears to substantiate Australian dentists' fear about lack of smokers' motivation to quit.

Our study is among the first internationally to determine rates of dentists' provision of smoking advice by linking patient recall to a specific consultation. Smokers reported low rates of detection of their smoking status from their dentist ( $n=40 / 124,32 \%)$. Further, few smokers reported that their dentist advised them to quit $(n=22 / 124,18 \%)$. Only 5\% $(n=6 / 124)$ of smokers recalled that their dentist suggested nicotine replacement therapy, despite promising evidence of its impact on cessation. ${ }^{7}$ Very few smokers amenable to the quit message, that is in a 'contemplative' or 'preparation' stage-of-change, recalled any smoking cessation advice strategy during their index consultation. These results reflect findings from the $\mathrm{UK}^{9,28}$ and demonstrate the persistent reluctance of dentists to provide smoking cessation advice despite recent calls from within the profession for them to do so. 
Our results invite reflection. While randomised controlled trials (RCTs) have been conducted to evaluate educational programmes for dentists to enhance their provision of smoking advice, ${ }^{1,29-31}$ it seems premature to embark on such programmes in the absence of more compelling evidence of what will make a real difference in patient outcomes. While patient alienation may not be a major barrier to smoking cessation advice by dentists, our findings suggest a disturbing lack of confidence among patients in their dentist's ability to provide effective smoking cessation advice. Over one third of our respondents $(n=213 / 623,34 \%)$ were unsure of whether their dentist knew how to stop patients from smoking. Further, when asked, 'if my dentist suggested that I quit, I would try', less than one third agreed. With such low expectations, it is not surprising that office-based dental interventions, similar to those reported in the United States, ${ }^{2-3}$ have failed.

Therefore, we support the argument, proposed elsewhere, ${ }^{12}$ that the efficacy of non-medical clinicians such as dentists in the delivery of smoking cessation advice needs to be proven conclusively through better trials. We recommend well-designed randomisedcontrolled studies to determine the acceptability and effectiveness of smoking cessation advice in diverse dental settings in various healthcare systems. Studies such as that by Smith et al. ${ }^{4}$ serve as a reminder that this field is fraught with barriers and disincentives. In the absence of more compelling evidence however, dentists will justifiably resist any calls to provide smoking cessation advice to their smoking patients.

Methodologically, we recognise that our sample may be biased as a result of achieving relatively modest consent rates from dentists and that of their patients. Of 135 dentists approached, only 78 (58\%) consented to participate and, while 1,160 patients completed pre-consultation questionnaires, we received only 623 postconsultation questionnaires (54\%). Further, smokers were significantly less likely to return post-consultation questionnaires, suggesting that our findings about the current rates of smoking cessation advice rates may be an over-estimate. Smokers who did not return questionnaires may have felt no need to do so if their dentist failed to raise the issue of smoking in the consultation. However, as self-reported smoking rates of dental patients in our sample $(n=302 / 1160,26 \%)$ were consistent with populationbased data, we are confident in the generalisability of smokers' views ascertained in our survey to the broader community. ${ }^{26} \mathrm{We}$ also cannot exclude the possibility that dentists modified their provision of smoking cessation counselling during the study, although this would appear unlikely in light of previous evidence. ${ }^{32}$ Patient expectations and recall may have been heightened as a result of their completion of pre-consultation questionnaires, however in the absence of validation studies this remains speculative.

The authors would like to thank the dentists and patients who participated in this project and Ms Mary Bourke for dedicated research assistance. This study was funded with a grant-in-aid from the National Heart Foundation of Australia and approved by the Ethics Review Committee (Royal Prince Alfred Hospital).

1. Cohen S J, Stookey G K, Katz B P, Drook C A, Christen A G. Helping smokers quit: a randomised controlled trial with private practice dentists. JAm DentAssoc 1989; 118: $41-45$.
2. Kentala J, Utrianen P, Pahkala K, et al. Can brief intervention through community dental care have an effect on adolescent smoking? Prev Med 1999; 29: 107-111.

3. Severson $\mathrm{H} H$, Andrews J A, Lichtenstein $\mathrm{E}$, et al. Using the hygiene visit to deliver a tobacco cessation program: results of a randomized clinical trial. J Am Dent Assoc 1998; 129: 993-999.

4. Smith SE, Warnakulasuriya K A A S, Feyerabend C, Belcher M, Cooper D J, Johnson N W. A smoking cessation program conducted through dental practices in the UK. $\mathrm{Br}$ DentJ 1998; 185: 299-303.

5. Rikard-Bell G C, Ward J. Australian dentists' educational needs for smoking cessation counselling. J Cancer Educ 2001: 16: 80-84.

6. Rikard-Bell G C, Ward J. Maximising response rates to a survey of dentists: a randomised trial. Aust Dent J2000; 45: 46-48.

7. Chestnutt I G, Binnie VI. Smoking cessation counselling - a role for the dental profession? BrDent J 1995: 179: 411-415.

8. Campbell HS, Sletten M, Petty T. Patient perceptions of tobacco services in dental offices. JAm Dent Assoc 1999; 130: 219-226.

9. John J H, Yudkin P, Murphy M et al.Smoking cessation interventions for dental patients- attitudes and reported practices of dentists in the Oxford region. BrDentJ 1997; 183: 359-364.

10. Martin L M, Bouquot J E, Wingo P A, Heath C W Jr. Cancer prevention in dental practice: oral cancer screening and tobacco cessation advice. J Public Health Dent 1996; 56: 336-340.

11. Allard, R H B. Tobacco and oral health: attitudes and opinions of European dentists; a report of the EU working group on tobacco and oral health. Int Dent J 2000; 50: $99-102$.

12. Fiore M C, Bailey W C, Cohen S J, et al. Treating Tobacco Use and Dependence. Clinical Practice Guidelines. Rockville, MD: US Department of Health and Human Services. Public Health service. June 2000

13. O'Keefe J, Lessio A, Kassirer B. A pilot smoking cessation program involving dental offices in the borough of East York, Ontario: an initial evaluation. J Can Dent Assoc 1995; 61: 65-67.

14. Fried $J \mathrm{~L}$, Cohen $\mathrm{L} A$. Maryland dentists' attitudes regarding tobacco issues. Clin Prev Dent 1992; 14: 10-16.

15. Campbell HS, Macdonald J M. Tobacco counselling among Alberta dentists. J Can DentAssoc 1994; 60: 218-226.

16. Brink S G, Gottlieb N H, McLeroy KR, Wisotzky M, Burdine J N. A community view of smoking cessation counselling in the practices of physicians and dentists. Public Health Rep 1994: 109: 135-142.

17. Tomar S L, Husten C G, Manley M W. Do dentists and physicians advise their patients to quit? JAm Dent Assoc 1996; 127: 259-265.

18. Rissel C. Hua M, Mansfield A, Burgess G. Second CSAHS Tobacco Control Plan 19992004. CSAHS, 1999.

19. Prochaska J O, Di Clemente C C. Transtheoretical therapy: toward a more integrative model of change. Psychother, Theory Pract 1982; 19: 276-288.

20. Ward J, Sanson-Fisher R. Accuracy of recall of opportunistic smoking cessation in general practice. Tobacco Control 1996; 5: 110-113.

21. Osborn $M$, Ward J, Boyle $C$. Effectiveness of telephone prompts when surveying general practitioners: a randomised trial. Aust Fam Physician 1996 Jan: Suppl 1: S41-43.

22. Dean A G, Dean J A, Coulombier D et al. Epi Info, Version 6: a word processing, database and statistics program for epidemiology on microcomputers. Atlanta: Centres for Disease Control and Prevention, 1994.

23. Donner A, Birkett N, Buck C. Randomization by cluster: Sample size requirements and analysis. Am J Epidemiol 1981; 114: 906-914.

24. SPSSX for Windows: base system user's guide Release 6.1: SPSS Inc. Chicago, 1994

25. Liang KY, Zeger $S$ L, Qaqish B. Multivariate regression analyses for categorical data. J Roy Soc Series B 1992; 54: 3-40.

26. NSW Health Survey 1997 (HOIST) Epidemiology and Surveillance Branch, NSW Health Department. Accessed, June 1999.

27. Humair J-P, Ward J. Smoking cessation strategies observed in videotaped general practice consultations. Am JPrev Med 1998; 14: 1-7.

28. Cowan C G, Gregg TA, Kee F. Prevention and detection of oral cancer: the views of primary care dentists in Northern Ireland. Br Dent J 1995; 179: 38-42.

29. Cohen S J, Christen A G, Katz B P. et al. Counselling medical and dental patients about cigarette smoking: the impact of nicotine gum and chart reminders. Am J Public Health 1987: 77: 313-316.

30. Wood G J, Cecchini J J, Nathason N, Hiroshige K. Office-based training in tobacco cessation for dental professionals. J Am Dent Assoc 1997; 128: 216-224.

31. Skegg J A. Dental programme for smoke-free promotion: attitudes and activities of dentists, hygienists, and therapists at training and 1 year later. NZ Dent J 1999; 95: 55-57.

32. Redman S, Dickinson J, Cochburn J et al. The assessment of reactivity in direct observation studies of doctor-patient interaction. Psychol \& Health 1989; 3: 17-28. 